\title{
Evaluation of exponential moving average application to smooth the power output of wind turbine with different control modes
}

\author{
Dinh Chung Phan, Ngọc An Luu
}

Faculty of Electrical Engineering, The University of Danang-University of Science and Technology, Vietnam

\begin{tabular}{|c|c|}
\hline Article Info & ABSTRACT \\
\hline Article history: & \multirow{11}{*}{$\begin{array}{l}\text { This paper focused on evaluating the application of exponential moving } \\
\text { average method into wind turbine to smooth its power output without an } \\
\text { energy storage system or an anemometer. Wind turbine control modes } \\
\text { including active power control mode and rotor speed control mode are } \\
\text { considered. For each control mode, two positions of the Exponential Moving } \\
\text { Average method in controller were compared to choose the best position. } \\
\text { Additionally, the impact of smoothing factor on wind turbine performance } \\
\text { was also considered to determine a reasonable value of the smoothing factor } \\
\text { for each control mode. Simulation results in MATLAB/Simulink indicated } \\
\text { that, for wind turbine using rotor speed control mode, the Exponential } \\
\text { Moving Average method should be applied to reduce the variation of actual } \\
\text { rotor speed signal while for wind turbine with the power control mode, it } \\
\text { should be used to smooth reference power signal. From the performance of } \\
\text { wind turbine with different smoothing factor values, we can suggest that the } \\
\text { smoothing factor value should be set at } 0.5 \text { and } 0.4 \text { for the power control } \\
\text { mode and the rotor speed control mode, respectively. }\end{array}$} \\
\hline Received Sep 5, 2020 & \\
\hline Revised Apr 26, 2021 & \\
\hline Accepted May 9, 2021 & \\
\hline & \\
\hline Keywords: & \\
\hline DFIG & \\
\hline EMA application & \\
\hline Power control & \\
\hline Rotor speed control & \\
\hline Smooth power output & \\
\hline
\end{tabular}

This is an open access article under the CC BY-SA license.

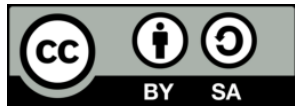

\section{Corresponding Author:}

Dinh Chung Phan

Faculty of Electrical Engineering

The University of Danang-University of Science and Technology

54 Nguyen Luong Bang, Danang, Vietnam

Email: pdchung@dut.udn.vn

\section{INTRODUCTION}

Electricity demand has been increased in many countries in the world while the potential of fossil sources has being decreased [1]. The exploiting of renewable energy resources including wind energy, solar energy, and so on to meet the increasing demand is necessary. In many countries, electricity generation from renewable energy resources met a significant percentage of load demand [1]. One of those sources is wind energy. However, the power output of wind turbine or wind farm is often fluctuation because of the natural variation of wind speed [2].

Depending on the position and capacity of wind farm, the wind farm can be connected to a weak grid or a strong one. When a wind farm supplies to a weak power system, this wind farm can bring some negative impact on the connected grid [3]. The main reason is the wind speed is often varied naturally while the wind turbine's power output is reliant on the cubic of the wind speed. Therefore, the wind farm's power output also fluctuated naturally and this leads to variation in voltage, frequency and so on, on the connected grid. Hence, the mitigation of power output fluctuation from wind turbines plays a significant role in reducing wind farm's negative impact.

To mitigate the power output variation of wind farm, many researches were carried out [4]-[13]. In these publications, many schemes to smooth wind farm's power output were proposed but they can be 
generally classified into two categories. The first category is based on a storage system [4], [7], [8], [12], [13] while the second one is developed from wind turbine's control system such as inertia control's kinetic energy, pitch angle adjustment, DC voltage control, and so on [5], [6], [9]. For the first group, by adjusting the amount of power charged/discharged from storage systems, it is easy to remain a constant or smooth power output of the wind farm; the use of storage systems, each wind turbine can track its maximum power point tracking (MPPT) curve during a low wind speed period to obtain a maximum energy output; however, we must invest an expensive storage system and pay maintenance cost [4]. In contrary to the first group, the second group does not require the investment of storage system, it is only based on the controller system of wind turbine. However, for this group, the wind turbine is hard to obtain its maximum power output $[5,7]$; moreover, the pitch control is often used to smooth the output power when the wind velocity is higher than the rated value; additionally, to use the pitch control and inertia control for smoothing the power output purpose, an anemometer is required [10], [11].

Exponential moving average (EMA) method was also used to smooth wind turbine's output power. The problem is that the EMA method is often accompanied with either a storage system or an anemometer [8], [14]. In [8], authors implemented the EMA method to calculate the reference power for the storage system's controller. In [14], the EMA method was used to smooth the reference power for wind turbine's controller; the input of this EMA block was calculated by using the output of anemometer. Practically, in many wind turbines, the output of anemometer is not used to calculate the power/rotor speed reference; in there, the power/rotor speed reference signal was calculated from the actual rotor speed/power output of wind turbine. Until now, the application of EMA method to these wind turbines, which use neither a storage system nor an anemometer, to smooth power output has not yet proposed.

The main contribution of this research is the application of the EMA method to wind turbines without a storage system or an anemometer to smooth their power output. The EMA method is only implemented into the rotor side converter's controller. For each wind turbine, we are going to consider two control modes including active power control mode and the rotor speed adjustment mode. For each control mode, two different EMA applications will be compared and evaluated to choose the best implementation. Another contribution is that in this paper, the reasonable value range of smooth factor in the EMA method for each control mode is going to be proposed. This evaluation and comparison are carried out via simulation results in MATLAB/Simulink.

\section{WIND TURBINE SYSTEM}

A wind turbine system consists of three main parts including turbine's blade, shaft system and generator [15]. Depending on the type of generator, wind turbines are classified into two categories including constant speed wind turbine and variable speed one. In the variable speed wind turbine configuration, a power electronic converter must be employed to interface to the connected grid. Thanks to this electronic converter, the variable speed wind turbine's controllability is better than the fixed speed wind turbine [16]. In the variable speed wind turbine category, the use of a doubly fed induction generator (DFIG) is generally more economical than other. Because in the DFIG wind turbine, the converter is only installed in the rotor side as Figure 1 [17], [18], and the size of rotor side converter (RSC) and grid side converter (GSC) are only about $30 \%$ of the DFIG capacity. Hence, the DFIG wind turbine is used in this research.

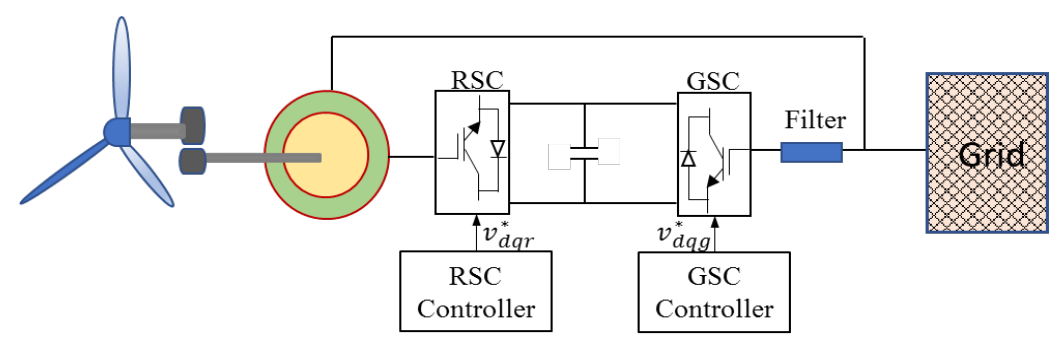

Figure 1. DFIG wind turbine

\subsection{Wind turbine}

The main purpose of the blade system is to absorb wind's kinetic energy to rotate its shaft. Normally, the blade system cannot absorb all kinetic energy of the wind, only a part of it can be converted to mechanical power on the wind turbine shaft. Its absorbing capability is represented via a power coefficient

Evaluation of exponential moving average application to smooth the power output .... (Dinh Chung Phan) 
$C_{p}(\lambda, \beta)$. This power coefficient is a function of pitch angle $\beta$ and tip-speed-ratio $\lambda$. The tip-speed-ratio is defined by [19].

$$
\lambda(t)=R \frac{\omega_{r}(t)}{V_{w}(t)}
$$

Where, $R$ is the blade length, $\omega_{r}$ and $V_{w}$ are rotor speed and wind speed, respectively. Mechanical power output of wind turbine blade is defined by [16].

$$
P_{m}(t)=\rho A C_{p}(\lambda, \beta) V_{w}^{3}
$$

where $\rho$ is air density and $A$ is the swept area of blade. Obviously, the power output of a wind turbine is proportional to the cubic of wind speed. Hence, if the velocity of wind is greater than the rated value, pitch control should be activated such that it can limit active power at rated value. Otherwise, wind turbine is expected to generate all available power. Because the power coefficient $C_{p}(\lambda, \beta)$ has a unique maximum point $\left(\lambda_{\text {opt }}, C_{\text {pmax }}\right)$ at each value of pitch angle $\beta$ [17], [20]. Therefore, during a low wind speed, the pitch angle is kept at zero and the wind turbine is controlled such as the power coefficient $C_{p}(\lambda, \beta)$ obtains its maximum $C_{\text {pmax }}$ or the wind turbine operates on its MPPT curve. By using (1), (2), $C_{p}=C_{p \max }$ and $\lambda=\lambda_{\text {opt }}$, we can get;

$$
P_{m}(t)=\rho A C_{p \max } V_{w}^{3}(t)=K_{o p t} \omega_{r}^{3}(t)
$$

where

$$
K_{o p t}=\rho A R^{3} C_{p \max } / \lambda_{o p t}^{3}
$$

\subsection{DFIG}

A doubly fed induction generator will convert the mechanical power on the generator shaft to electrical power output. In DFIG, the stator winding is often connected directly to the connected grid while the rotor winding is indirectly connected to the grid via a back-to-back converter as Figure 1 . In $d q$ frame where $d$-axis is ranged along the stator flux vector and neglecting the resistance of the stator winding, the DFIG wind turbine is described as [21].

$$
v_{d q r}(t)=R_{r} i_{d q r}(t)+\sigma L_{m} \frac{d i_{d q r}(t)}{d t}+\omega_{s} \sigma s(t) L_{m} \Theta i_{d q r}(t)+\frac{s(t) L_{m}}{L_{s}} \Theta\left[\begin{array}{c}
V_{s} \\
0
\end{array}\right]
$$

Where

$$
\begin{aligned}
& \Theta=\left[\begin{array}{cc}
0 & -1 \\
1 & 0
\end{array}\right] ; \quad \sigma=\frac{L_{r}}{L_{m}}-\frac{L_{m}}{L_{s}} ; \\
& s(t)=1-\frac{\omega_{r}(t)}{\omega_{s}} ;
\end{aligned}
$$

$R_{r}$ : the resistance of rotor winding;

$L_{r}, L_{s}$, and $L_{m}$ : the inductance of rotor winding, stator winding and magnetizing core;

$v_{d q r}$ and $i_{d q r}$ : voltage and current in $d q$ frame in the rotor side;

$\omega_{r}$ and $\omega_{s}$ : the rotational speed of flux in the rotor and stator side;

$s$ : slip factor;

$V_{S}$ : voltage magnitude in the stator side.

Active power output of DFIG is the summation of power output in the stator and rotor side [20].

$$
P_{e}(t)=P_{s}(t)+P_{r}(t)=(1-s(t)) P_{s}(t)
$$

Where

$$
\begin{aligned}
& P_{s}=\operatorname{Re}\left\{\frac{2}{3}\left(v_{d s}(t)+j v_{q s}(t)\right)\left(i_{d s}(t)-j i_{q s}(t)\right)\right\}=\frac{2}{3} \operatorname{Re}\left\{V_{s} i_{q s}(t)+j V_{s} i_{d s}(t)\right\} \\
& =\frac{2}{3} V_{s} i_{q s}(t)=-\frac{2}{3} \frac{L_{m}}{L_{s}} V_{s} i_{q r}(t) .
\end{aligned}
$$


The motion equation of DFIG wind turbine can be described as:

$$
J \frac{d}{d t} \omega_{r}(t)=T_{m}(t)-T_{e}(t)
$$

where $J$ is the wind turbine system's inertia constant, $T_{m}$ is mechanical torque on the shaft, and $T_{e}$ is electrical torque defined as:

$$
T_{e}(t)=\frac{P_{e}(t)}{\omega_{r}(t)}=-\frac{2}{3} \frac{L_{m}}{L_{s} \omega_{s}} V_{s} i_{q r}(t)
$$

Clearly, both the electric power in total and the rotor speed are reliant on the $q$-axis current component in the rotor side.

\subsection{Control modes of RSC controller}

As above mention, a back-to-back converter is employed to link the rotor winding of DFIG and the grid. Thanks for this converter, the DFIG wind turbine can control to extract maximum power output during low wind speed. According to (1), (3), and (8)-(11), to obtain maximum power output, the wind turbine can operate under two control modes including power control mode and rotor speed control mode [22]. Ideally, from (1) and (3) we can measure instantaneous wind speed to calculate reference signal and then the controller will adjust actual signal among this reference. However, the use of anemometer is uneconomical, and it makes power output more fluctuation. To overcome this drawback, the DFIG wind turbine can use actual active power or rotor speed as an input signal to determine the reference rotor speed or the reference power output. Therefore, two control modes can apply to RSC as Figure 2. Until now, many kinds of control scheme have been suggested but PI control is still well-known. In this research, the RSC controller based on proportional-integral (PI) control is used [22].

In Figure 2, the superscription “*” denotes for reference signal. In Figure 2(a) which represents to the rotor speed control mode, the actual electric power $P_{e}$ is used to calculate the reference rotor speed $\omega_{r}^{*}$ and the rotor speed controller will adjust such that the actual rotor speed $\omega_{r}$ and the d-axis component current $i_{d r}$ are reached to their reference value $\omega_{r}^{*}$ and $i_{d r}^{*}$, respectively. Likely, in the power control mode, the actual rotor speed is used to calculate the reference power and then the power controller will adjust to make the actual power output reach to this reference power. The output of the rotor speed controller or the power controller $v_{d q r}^{*}$ will be transformed to three-phase voltage and then it is sent to the pulse wide modulation (PWM) block. With pulses generated by PWM block, if valves in RSC are operated ideally, the voltage in the rotor side in $d q$ frame $v_{d q r}$ will be equal $v_{d q r}^{*}$ and it means the objective of rotor speed control in Figure 2(a) or power control in Figure 2(b) is achieved. It is important to know that this research only focus on the RSC controller hence the GSC controller is used as that in the reference [22].

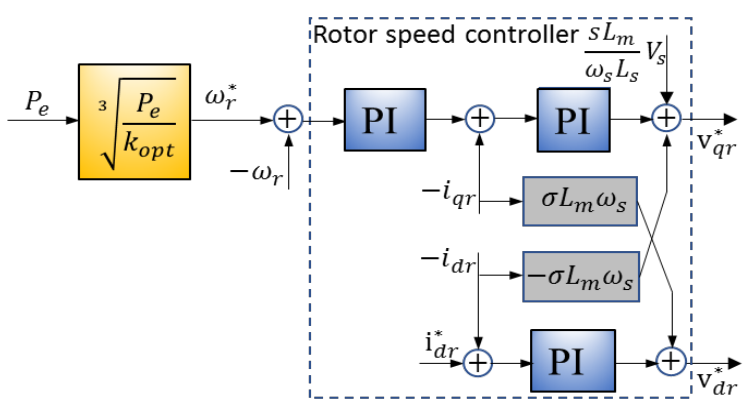

(a)

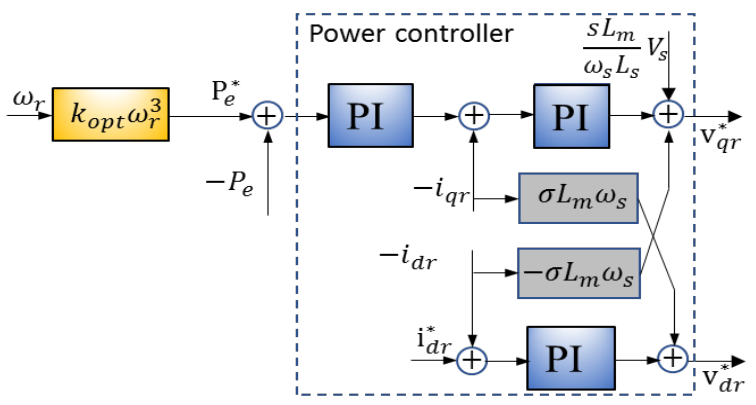

(b)

Figure 2. RSC controller modes; (a) rotor speed control, (b) power control

\section{SCHEME TO SMOOTH POWER OUTPUT}

To smooth power output, in this research, we use the EMA method. This method has ever proposed in wind turbine [8], [23], [24]. However, this research only focuses on the wind turbine without both a storage system and an anemometer. In this research, we apply EMA to reduce the reference signal or actual signal in the RSC controller of wind turbine. 


\subsection{Exponential moving average}

Exponential moving average (EMA) is also named as an exponentially weighted moving average where weighted factor is decreased exponentially. The EMA modelling is shown in Figure 3 and it is described as [6].

$$
x_{e m a}(t)=x_{e m a}(t-T)+\alpha\left(x(t)-x_{e m a}(t-T)\right) \text {, }
$$

where,

$x$ : the input signal which we need to smooth,

$x_{\text {ema }}:$ the output of EMA,

$T$ : time period,

$\alpha$ : smoothing factor of EMA, $0<\alpha<1$.

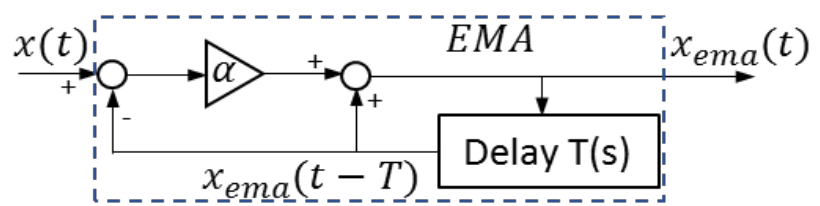

Figure 3. Modelling of EMA method

To evaluate the impact of the smoothing factor to the output of EMA, here we take an example of EMA application to smooth the outgoing mechanical power of a wind turbine. We suppose that the outgoing mechanical power varies as the doted curve as shown in Figure 4. Here, $T=5 \mathrm{~s}$ and different values of smoothing factor are considered. The output of EMA is indicated in Figure 4.

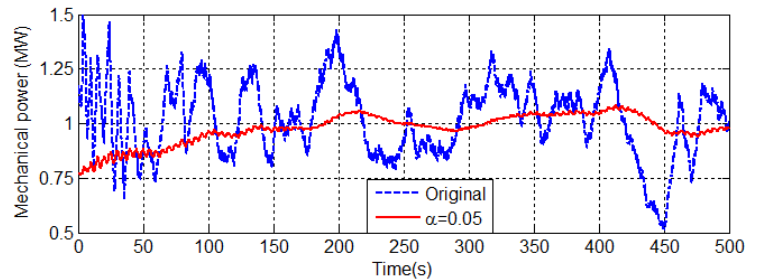

(a)

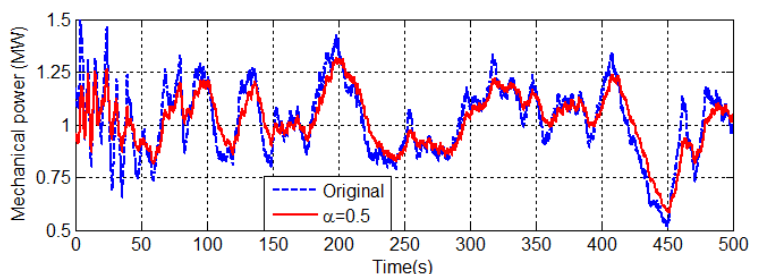

(c)

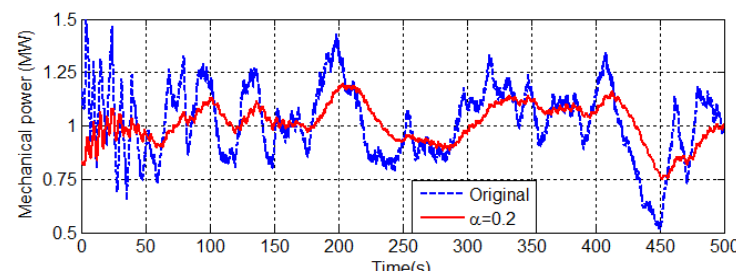

(b)

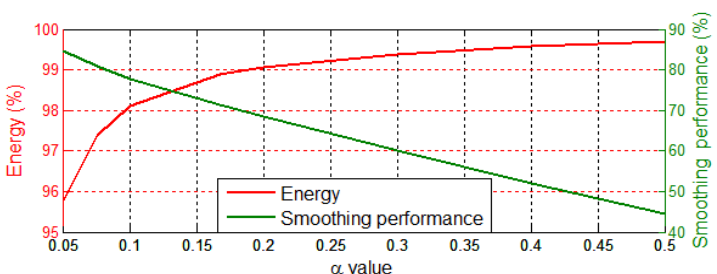

(d)

Figure 4. An example of EMA application to smooth the mechanical power output of wind turbine, (a) $\alpha=0.05$, (b) $\alpha=0.2$, (c) $\alpha=0.5$, (d) Energy and smoothing performance versus $\alpha$ value

In Figure 4, the original case is the EMA's input signal which is the mechanical power withdrawn from a wind turbine. Figures 4(a), 4(b), and 4(c) implied that when the lower smoothing factor, the smoother power output is. Normally, to evaluate the performance of a smoothing method, the maximum energy function and smoothing function [4] are used. In here, we propose the maximum energy function of the output signal comparing to that of input signal, $E \%$, as (13) while the smoothing performance of EMA, $S P \%$, is defined as (14). As (14), if the smoothing performance value is $100 \%$, the smoothing function of output 
signal becomes zero or the output signal is completely smooth. In Figure 4(d), the impact of the smoothing factor on the energy and smoothing performance of output signal are demonstrated. Obviously, as $\alpha \geq 0.3$ the energy output is insignificantly increased while the smoothing performance is reduced linearly. However, in terms of energy output, the smoothing factor of 0.5 should be chosen to obtain a high efficiency of wind turbine.

$$
\begin{aligned}
& E \%=\frac{\int x_{e m a} d t}{\int x d t} 100 \% \\
& S P \%=\frac{\int|d x / d t| d t-\int\left|d x_{e m a} / d t\right| d t}{\int|d x / d t| d t} 100 \%
\end{aligned}
$$

\subsection{EMA application}

In this section, we apply the EMA method into a wind turbine with different control mode. Two control modes considered in this research are the power control mode and the rotor speed control mode. For the wind turbine with the rotor speed control mode, EMA is applied to reduce the variation of reference rotor speed signal as Figure 5(a) and the actual rotor speed signal as Figure 5(b). For the wind turbine with the power control mode, we propose as Figure 6(a) and Figure 6(b) for smoothing the reference active power and the actual power signal, respectively.

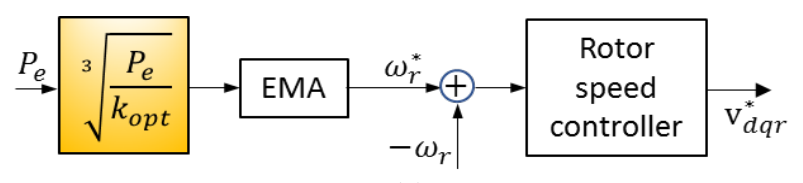

(a)

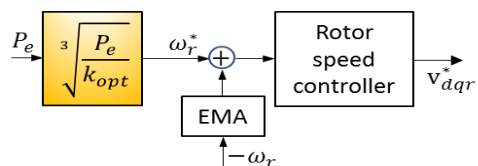

(b)

Figure 5. EMA application in the wind turbine with the rotor speed control mode, (a) smoothing reference rotor speed signal, (b) smoothing the actual rotor speed signal

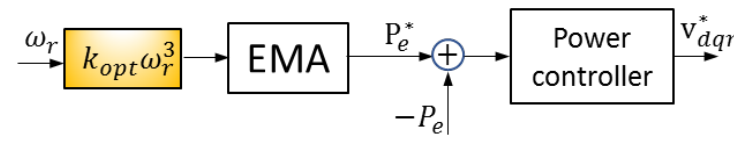

(a)

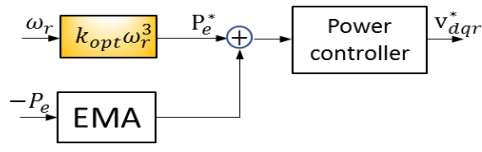

(b)

Figure 6. EMA application in the wind turbine with the power control mode, (a) smoothing reference power signal, (b) smoothing the actual power signal

\section{RESULTS AND DISCUSSION}

To verify the EMA application to wind turbine in different control modes, in this research, we use MATLAB/Simulink to simulate a 1.5 MW wind turbine whose power coefficient is described as [20], [25]. We also suppose that the wind speed profile is shown as Figure 7.

$$
\begin{aligned}
& C_{p}(\lambda, \beta)=0.5176\left(\frac{116}{\lambda_{i}}-0.4 \beta-5\right) e^{-\frac{21}{\lambda_{i}}}+0.0068 \lambda \\
& \frac{1}{\lambda_{i}}=\frac{1}{\lambda+0.008 \beta}-\frac{0.035}{\beta^{3}+1}
\end{aligned}
$$

Here, we will use the time period $T=5 s$ and the smoothing factor $\alpha=0.5$ for all EMA application. Simulation results are used to compare and determine the best EMA application for the wind turbine with two control modes. After that the performance of wind turbine with different smoothing factor values is considered to determine the smoothing factor value for each control mode. To evaluate the efficiency of EMA application to smooth power output, we will use the smoothing function $\Delta P_{\text {smooth }}$ and the electrical energy output of DFIG wind turbine as equation (17)-(18) [4].

$$
\Delta P_{\text {smooth }}=\int\left|\frac{d}{d t} P_{e}\right| d t,
$$


$E=\int P_{e} d t$

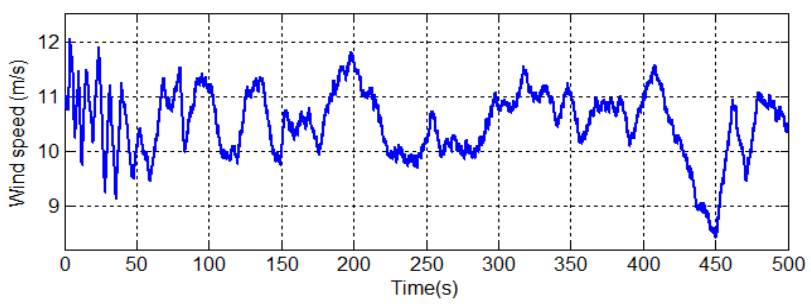

Figure 7. Wind speed profile

The power output of wind turbine is smooth if the smoothing function value is small. However, we always expect to withdraw a maximum electrical yield from the wind turbine and hence, the case of EMA application with the small value of smoothing function and the high value of electrical energy will be chosen and recommended.

\subsection{Wind turbine with rotor speed control mode}

The key target of this subsection is to evaluate the EMA application into the wind turbine which is designed to control the rotor speed. Here, we consider two cases of EMA applications. In the first case, EMA is utilized to reduce the variation of actual rotor speed signal and in the seconds one, EMA is used to smooth the reference rotor speed signal as Figure 5. The simulation results are indicated in Figure 8 where the black curve is the result of wind turbine without EMA application; the red curve and the blue curve stand for the wind turbine with the EMA application in the reference rotor speed signal and the actual rotor speed signal, respectively.

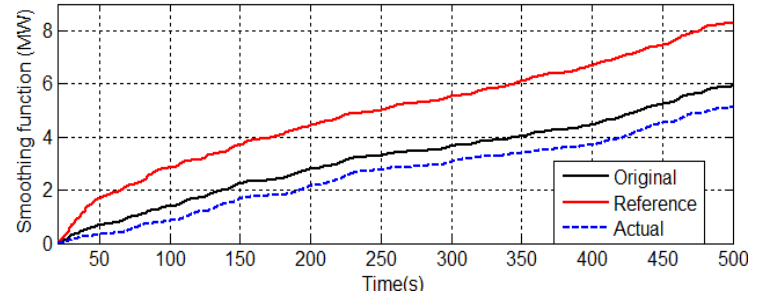

(a)

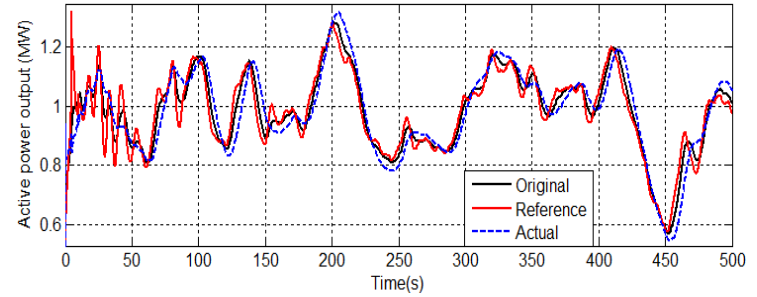

(b)

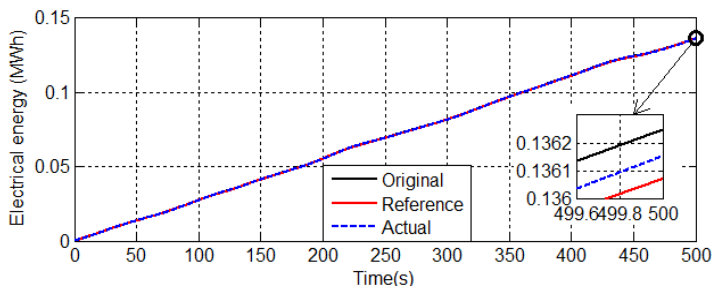

(c)

Figure 8. Simulation results in wind turbine with the rotor speed control mode, (a) smoothing function, (b) power output, (c) electrical energy

As can be seen from Figure 8(a), by smoothing the actual rotor speed signal, the smoothing function is smaller than that by smoothing the reference rotor speed signal and it is also smaller than that of the original case. It means the EMA application to smooth the actual rotor speed signal make the power output become smoother. This is also seen in Figure 8(b) which plots the actual active power output of the wind turbine. In terms of energy output in Figure 8(c), when we apply EMA to smooth the outgoing power of the wind turbine with rotor speed control, the energy output at the end of simulation period is smaller than that of 
the original case. However, in comparison of two cases of EMA applications, by smoothing the actual rotor speed signal we can extract more energy output than that of another case. Obviously, at the end of simulation period, by smoothing the actual rotor speed signal, we can get $0.13617 \mathrm{MWh}$ while by smoothing the reference rotor speed signal, the data is only $0.13609 \mathrm{MWh}$. Comparing to the original case, we only get $99.93 \%$ and $99.88 \%$ for the actual rotor speed signal and the reference rotor speed signal, respectively. Therefore, for the wind turbine controlling the rotor speed, EMA should be applied to reduce the variation of actual rotor speed signal.

\subsection{Wind turbine with power control mode}

The key intention of this section is to evaluate the application of EMA into the wind turbine which controls the power output. This section, we also consider two cases of EMA applications as Figure 6 . The results are indicated in Figure 9. In this figure, the black curve is the results of the wind turbine without EMA application; the red curve and the blue curve are also the wind turbine with EMA application in the reference power signal and the actual power signal, respectively.

It is clearly that in the case of EMA application into the actual power signal, the smoothing function value is higher than the original case, Figure 9(a). By contrast, when we apply EMA to the reference power signal the smoothing function value is lower than that of the original case. It means the EMA application to the reference signal has a better performance than that of the case of smoothing actual power. From the Figure 9(b), by smoothing the reference power signal, the power output is smoother than other cases. Concerning to energy output, Figure 9c implies that by smoothing the reference power signal the wind turbine can withdraw a higher energy than the case of actual power signal. However, it cannot be higher than that of the original case. By comparing to the original case, the actual power signal case only withdraws $99.88 \%$ while the data of the reference power signal case is up to $99.93 \%$. In conclusion, when EMA is applied to smooth the outgoing power of a wind turbine with the power control mode, EMA should apply to the reference power signal.

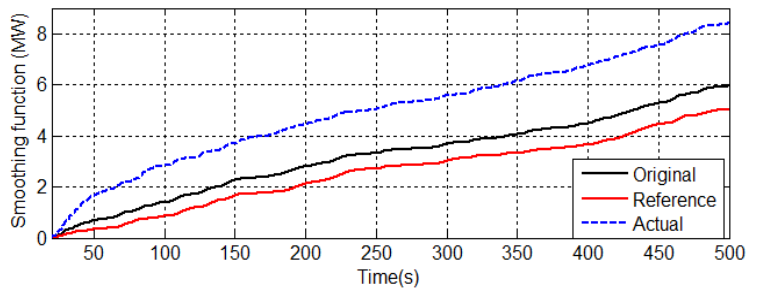

(a)

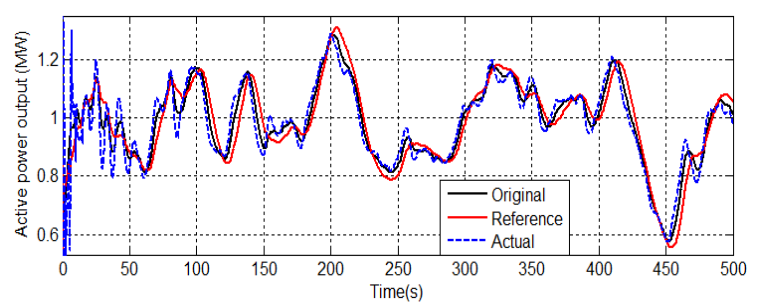

(b)

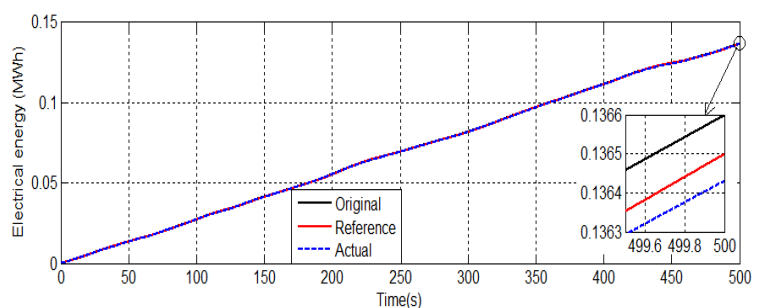

(c)

Figure 9. Simulation results in wind turbine with the power control mode; (a) smoothing function, (b) power output, (c) electrical energy

\subsection{Impact of the smoothing factor on wind turbine performance}

The aim of this subsection is to consider the impact of the smoothing factor on the wind turbine performance and to determine the smoothing factor value $\alpha$ for each control mode. Here, for the power control mode, we apply the EMA method to smooth the reference power signal while for the rotor velocity control mode, the EMA method is to reduce the variation of the actual rotor speed. To obtain this purpose, the performance of wind turbine with different values of $\alpha$ is considered. Results are shown in Figure 10.

In terms of electrical energy output at the end of simulation, Figure 10(a) indicated that as $0.3 \leq \alpha \leq 0.4$, the wind turbine with the rotor velocity control mode can extract more electrical energy than 
that with the power control mode; however, this conclusion is opposite as $0.45 \leq \alpha \leq 0.5$; with $0.4 \leq \alpha \leq 0.45$, the energy output of wind turbines is the same. Concerning to the smoothing function, the power control mode makes the smoothing function higher than the case of the rotor velocity adjustment mode; however, both of them, the smoothing function reaches to the smallest value as $\alpha=0.4$; additionally, the difference in the smoothing function value of two control modes becomes insignificant as the $\alpha$ value is approached to 0.5 . Therefore, we should set $\alpha=0.5$ if the power control mode is used; and as we use the rotor speed control mode, the $\alpha$ value should be set at 0.4 .

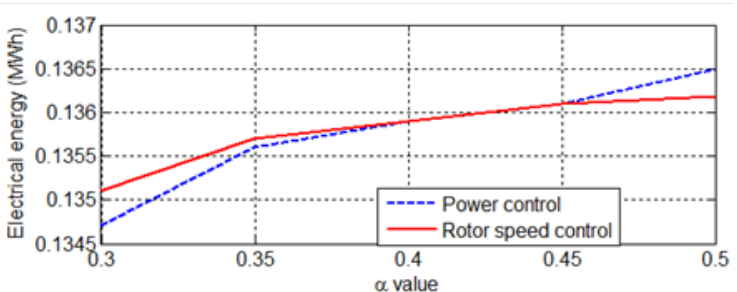

(a)

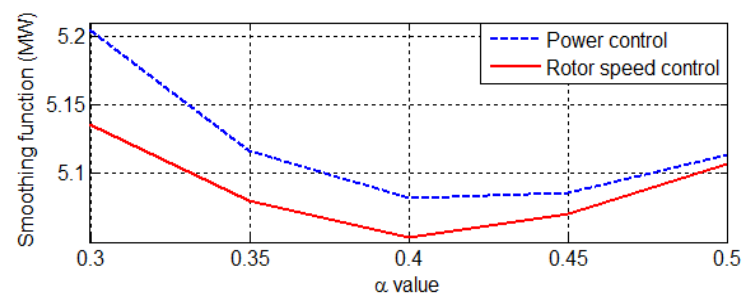

(b)

Figure 10. Comparing simulation results in wind turbine performance with the power control mode to that with the rotor speed control mode; (a) energy output, (b) smoothing function

\section{CONCLUSION}

This research considered the implementation of EMA into wind turbine to smooth power output. Two wind turbines are studied in this research, the first one is wind turbine with power control and the second one is the wind turbine with rotor speed control. From simulation research indicate that, with wind turbine using rotor speed control, EMA should apply to reduce the variation of actual rotor speed signal while for wind turbine with power control, EMA should apply to smooth reference power signal. Generally, if the EMA method is applied in the power control mode, the factor value should set 0.5 while by using the rotor speed control mode, the smoothing factor should be 0.4 .

\section{REFERENCES}

[1] D. Gielen et al., "Global Energy Transformation: A Roadmap to 2050," IRENA, International Renewable Energy Agency, 2018. [Online]. Available: https://www.irena.org//media/Files/IRENA/Agency/Publication/2018/Apr/IRENA_Report_GET_2018.pdf.

[2] I. Graabak and M. Korpås, "Variability Characteristics of European Wind and Solar Power Resources-A Review," Energies, vol. 9, no. 6, 2016, Art. no. 449, doi: 10.3390/en9060449.

[3] Y. Zhou, D. D. Nguyen, P. C. Kjaer, and S. Saylors, "Connecting Wind Power Plant with Weak Grid - Challenges and solutions," 2013 IEEE Power \& Energy Society General Meeting, Vancouver, BC, 2013, pp. 1-7, doi: 10.1109/PESMG.2013.6672755.

[4] A. M. Howlader, N. Urasaki, A. Yona, T. Senjyu, and A. Y. Saber, "A Review of Output Power Smoothing Methods for Wind Energy Conversion Systems," Renewable and Sustainable Energy Reviews, vol. 26, pp. 135-146, 2013, doi: 10.1016/j.rser.2013.05.028.

[5] K. A. Naik and C. P. Gupta, "Output Power Smoothing and Voltage Regulation of a Fixed Speed Wind Generator in the Partial Load Region Using STATCOM and a Pitch Angle Controller," Energies, vol. 11, no. 1, 2017, Art. no. 58, doi: https: 10.3390/en11010058.

[6] A. Pratap, N. Urasaki, and T. Senju, "Control Strategies for Smoothing of Output Power of Wind Energy Conversion Systems," International Journal of Emerging Electric Power Systems, vol. 14, no. 6, pp. 525-534, 2013, doi: 10.1515/ijeeps-2012-0030.

[7] M. Jabir, H. A. Illias, S. Raza, and H. Mokhlis, "Intermittent Smoothing Approaches for Wind Power Output: A Review," Energies, vol. 10, no. 10, p. 1572, 2017, doi: 10.3390/en10101572.

[8] M. R. I. Sheikh and J. Tamura, "Smoothing Control of Wind Farm Output Fluctuations by Fuzzy Logic Controlled SMES," International Journal of Electrical and Computer Engineering (IJECE), vol. 1, no. 2, pp. 119-134, 2011, doi: 10.11591/ijece.v1i2.181.

[9] A. M. Howlader, N. Urasaki, T. Senjyu, A. Uehara, A. Yona, and A. Y. Saber, "Output Power Smoothing of Wind Turbine Generation System for the 2-MW Permanent Magnet Synchronous Generators," 2010 International Conference on Electrical Machines and Systems, Incheon, 2010, pp. 452-457.

[10] A. Abedini, G. Mandic, and A. Nasiri, "Wind Power Smoothing Using Rotor Inertia Aimed at Reducing Grid Susceptibility," 2008 34th Annual Conference of IEEE Industrial Electronics, Orlando, FL, 2008, pp. 1445-1451, doi: 10.1109/IECON.2008.4758166. 
[11] Y. Zhu, H. Zang, L. Cheng, and S. Gao, "Output Power Smoothing Control for a Wind Farm Based on the Allocation of Wind Turbines," Applied Science, vol. 8, no. 6, 2018, Art. no. 980, doi: 10.3390/app8060980.

[12] K. Rabyi and H. Mahmoud, "Energy Storage of DFIG Based Wind Farm Using D-STATCOM," International Journal of Electrical and Computer Engineering (IJECE), vol. 9, no. 2, pp. 761-770, 2019, doi: 10.11591/ijece.v9i2.pp761-770.

[13] N. S. Jayalakshmi, D. N. Gaonkar, and S. K. Jain., "Power Smoothing Method of PMSG Based Grid Integrated Wind Energy Conversion System Using BESS/DSTATCOM," International Journal of Power Electronics and Drive System (IJPEDS), vol. 10, no. 4, pp. 1969-1976, Dec. 2019, doi: 10.11591/ijpeds.v10.i4.pp1969-1976.

[14] X. Lyu, J. Zhao, Y. Jia, Z. Xu, and K. P. Wong, "Coordinated Control Strategies of PMSG-based Wind Turbine for Smoothing Power Fluctuations," IEEE Transactions on Power Systems. vol. 34, no. 1, pp. 391-401, 2019, doi: 10.1109/TPWRS.2018.2866629.

[15] H. Becheri, I. K. Bousarhanne, A. Harrouz, H. Glaoui, and T. Belbekri, "Maximum Power Point Tracking of Wind Turbine Conversion Chain Variable Speed Based on DFIG," International Journal of Power Electronics and Drive System (IJPEDS), vol. 9, no. 2, pp. 527-535, Jun. 2018, doi: 10.11591/ijpeds.v9.i2.pp527-535.

[16] A. M. Thin and N. S. Y. Kyaing, "Performance Analysis of Doubly Fed Induction Generator Using Vector Control Technique," International Journal of Electrical and Computer Engineering (IJECE), vol. 5, no. 5, pp. 929-938, Oct. 2015, doi: 10.11591/ijece.v5i5.pp929-938.

[17] I. E. Karaoui, M. Maaroufi, and B. Bossoufi, "Robust Power Control Methods for Wind Turbines Using DFIGGenerator," International Journal of Power Electronics and Drive System (IJPEDS), vol. 10, no. 4, pp. 2101-2117, Dec. 2019, DOI: 10.11591/ijpeds.v10.i4.pp2101-2117.

[18] A. M. S. Yunus, M. Saini, and A. A. Siada, "Dynamic Performance Comparison of DFIG and FCWECS during Grid Faults," TELKOMNIKA Telecommunication Computing Electronics and Control, vol. 17, no. 2, pp. 1040-1046, Apr. 2019, doi: 10.12928/telkomnika.v17i2.11747.

[19] B. Rached, M. Elharoussi, and E. Abdelmounim, "Design and Investigations of MPPT Strategies for a Wind Energy Conversion System Based on Doubly Fed Induction Generator," International Journal of Electrical and Computer Engineering (IJECE), vol. 10, no. 5, pp. 4770-4781, 2020, doi: 10.11591/ijece.v10i5.pp4770-4781.

[20] N. Cherfia and D. Kerdoun, "Wind Energy Conversion Systems Based on a DFIG Controlled by Indirect Vector Using PWM and SVM," International Journal of Electrical and Computer Engineering (IJECE), vol. 6, no. 2, pp. 549-559, Apr. 2016, DOI:10.11591/ijece.v6i2.7858.

[21] D. C. Phan and T. H. Trinh, "Maximum Power Extraction Method for Doubly-fed Induction Generator Wind Turbine," International Journal of Electrical and Computer Engineering (IJECE), vol. 8, no. 2, pp. 711-722, 2018, doi: 10.11591/ijece.v8i2.pp711-722.

[22] L. M. Fernandez, C. A. Garcia, and F. Jurado, "Comparative Study on the Performance of Control Systems for Doubly Fed Induction Generator (DFIG) Wind Turbines Operating with Power Regulation,” Energy, vol. 33, no. 9, pp. 1438-1452, 2008, doi: 10.1016/j.energy.2008.05.006.

[23] M. A. Chowdhury, N. Hosseinzadeh, and W. Shen, "Fuzzy Logic Systems for Pitch Angle Controller for Smoothing Wind Power Fluctuations during Below Rated Wind Incidents," 2011 IEEE Trondheim PowerTech, Trondheim, 2011, pp. 1-7, doi: 10.1109/PTC.2011.6019306.

[24] M. A. Chowdhury, N. Hosseinzadeh, and W. X. Shen, "Smoothing Wind Power fluctuations by Fuzzy Logic Pitch Angle Controller," Renewable Energy, vol. 38, no. 1, pp. 224-233, 2012, doi: 10.1016/j.renene.2011.07.034.

[25] I. Yasmine, E. B. Chakib, and B. Badre, "Power Control of DFIG-Generators for Wind Turbines Variable-Speed," International Journal of Power Electronics and Drive System (IJPEDS), vol. 8, no. 1, pp. 444-453, Mar. 2017, doi: 10.11591/ijpeds.v8.i1.pp444-453.

\section{BIOGRAPHIES OF AUTHORS}

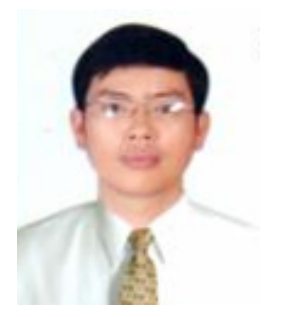

Dinh Chung Phan has been a lecture at Faculty of Electrical engineering, The University of Danang-University of Science and Technology in Vietnam since 2004. He obtained Engineering Degree, Master Degree and Philosophy Degree in electrical engineering from The University of Danang-University of Science and Technology in 2004, Dongguk University in Korea in 2011, and Kanazawa University in Japan in 2017, respectively. His researches are in fields of renewable energy, power system and control. Further info on his homepage: http://scv.udn.vn/phandinhchung

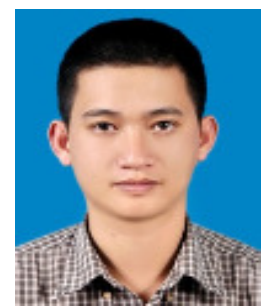

Ngoc An Lưu has been a lecture at Faculty of Electrical engineering, The University of DanangUniversity of Science and Technology in Vietnam since 2005. He obtained Engineering Degree, Master Degree and Philosophy Degree in electrical engineering from The University of DanangUniversity of Science and Technology in 2004, National Cheng Kung University in Taiwan in 2010, and Grenoble Institute of Technology in France in 2014, respectively. His researches are in fields of renewable energy, power system and energy management. Further info on his homepage: http://scv.udn.vn/lungocan 